\title{
Influência da cultura antecessora e da adubação nitrogenada na produtividade de milho em sistema plantio direto e solo preparado
}

\author{
Influence of the previous winter crop and nitrogen fertilization to corn productivity in notillage \\ and conventional tillage
}

\author{
Waldo Alejandro Rubén Lara Cabezas ${ }^{1}$ Bruno José Rodrigues Alves ${ }^{2}$ \\ Segundo Sacramento Urquiaga Caballero ${ }^{3}$ Denise Garcia de Santana ${ }^{4}$
}

\section{RESUMO}

Na região do Cerrado, parte da adubação de cobertura no milho poderia ser antecipada à semeadura do milho visando acelerar a decomposição de resíduos da cultura antecessora. Os objetivos deste experimento foram: a) avaliar a produtividade de milho em sucessão à nabo forrageiro e milheto, na presença e ausência de adubação nitrogenada de cobertura e b) avaliar a eficiência de recuperação de $\mathrm{N}$ adubo na planta e quantificar a volatilização de $\mathrm{N}-\mathrm{NH}_{3}$ do fertilizante nitrogenado aplicado em sistema plantio direto $(S P D)$ e em solo preparado $(S P)$. $O$ delineamento experimental utilizado foi blocos casualizados, em esquema de faixas, com quatro repetições. Até o florescimento, a produção de massa de matéria seca (MMS) e acumulação de $N$ na parte aérea do nabo forrageiro foi de, respectivamente, 2.274 e $53,0 \mathrm{~kg}$ $\mathrm{ha}^{-1}$, sob SPD, e 2.546 e 61,6kg ha-1, sob SP. No caso do milheto, os resultados obtidos foram 5.202 e $107,8 \mathrm{~kg} \mathrm{ha}^{-1}$, em SPD, e 5.101 e 104,1 kg ha- em SP. Até a semeadura do milho em SPD, após o acamamento das culturas de inverno, foram liberados 77,3 e 130,7kg ha de $\mathrm{N}$ na sucessão nabomilho e milheto-milho, respectivamente. Na condição de SP, as culturas de inverno foram incorporadas ao solo antes da semeadura do milho. Na cultura do milho, a perda por volatilização de $\mathrm{N}_{-} \mathrm{NH}_{3}$ foi inferior a 2,0\% do $\mathrm{N}$-aplicado em pré-semeadura $\left(71,3 \mathrm{~kg} h \mathrm{a}^{-1}\right.$ de $N$ na proporção $4: 1$, uréia:sulfato de amônio) e $14 \%$ do $N$ aplicado $\left(5 \mathrm{~kg} \mathrm{ha}^{-1}\right) \mathrm{em}$ cobertura $\left(35,7 \mathrm{~kg} \mathrm{ha}^{-1}\right.$ de $\mathrm{N}$-sulfato de amônio), avaliadas em SPD e SP, na sucessão nabo-milho. Em SPD, a eficiência da fertilização foi 57,1 e 42,1\% do N-aplicado na sucessão milheto-milho e nabo-milho, respectivamente. Em SP, 46,8 e 46,3\%, respectivamente. A adubação nitrogenada promoveu um acréscimo médio de $2.396 \mathrm{~kg} \mathrm{ha}^{-1}$ de grãos na sucessão milheto-milho, em SPD, comparada à testemunha não adubada. Este acréscimo foi de $895 \mathrm{~kg} \mathrm{ha}^{-1}$ de grãos na sucessão nabo-milho, sob SPD, e de respectivamente, 1.166 e $166 \mathrm{~kg} \mathrm{ha}^{-1}$ de grãos nas sucessões milheto-milho e nabomilho, em SP.
Palavras-chave: fertilização em pré-semeadura, Zea mays, plantas de cobertura do solo, eficiência do fertilizante, ${ }^{15} \mathrm{~N}$, volatilização de amônia.

\section{ABSTRACT}

In the Cerrado region a proportion of the top dressed $N$ for corn might be applied to the previous cover crop. This could accelerate the decomposition rate and increase overall $N$ availability to corn. Therefore, the objectives of this experiment were: a) to evaluate maize productivity after oil radish and millet grown in winter with and without nitrogen applied and $b$ ) to determine the efficiency of recovery of $N$ fertilizer by corn and quantify the losses by volatilization of ammonia of $N$ fertilizers in no-tillage (NT) and conventional tillage $(C T)$. The experimental design was a randomized complete block in strips with four replications. At flowering, the dry matter production and $N$ accumulation of the oil radish were, respectively, 2,274 and $53.0 \mathrm{~kg} \mathrm{ha}^{-1}$ under $\mathrm{NT}$, and 2,546 and $61.6 \mathrm{~kg} \mathrm{ha}^{-1}$ under CT. For millet the results obtained were 5,202 and $107.8 \mathrm{~kg} \mathrm{ha}^{-1}$ under NT, and 5,101 and $104.1 \mathrm{~kg} \mathrm{ha}^{-1}$ under CT. Until the seeding of the maize under NT, after desiccation by knife rolling the winter crops,

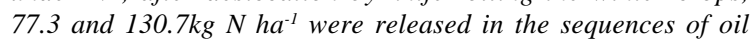
radish - maize and of millet - maize, respectively. Under CT the winter crops were incorporated into the soil before the seeding of the maize. In the growth cycle of corn the losses of $N$ via ammonia volatilization were less than $2.0 \%$ of the $N$

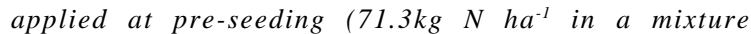
urea:ammonium sulphate of 4:1) and $14 \%$ of the $N$ at the 6leaf stage $(35.7 \mathrm{~kg} \mathrm{~N} \mathrm{ha-1}$ of ammonium sulphate), evaluated in NT and CT in the sequence oil radish - corn. Under NT the fertilizer- $N$-use-efficiency was 57.1 and $42.1 \%$ of the $N$ applied in the sequence millet - corn and oil radish-maize, respectively. Under CT these values were 46.8 and $46.3 \%$, respectively. The application of $N$ fertilizer caused a mean yield increase of $2,396 \mathrm{~kg}_{\mathrm{g}}$ rain ha-1 in the sequence millet-corn under NT compared to the non-fertilized control. These increase under

${ }^{1}$ Engenheiro Agrônomo, Doutor, Professor substituto, Universidade Federal de Uberlândia (UFU), C.P. 593, 38406-067, Uberlândia, MG. E-mail: waldolar@triang.com.br. Autor para correspondência.

${ }^{2}$ Engenheiro Agrônomo, Doutor, Pesquisador científico, Embrapa - Agrobiologia, km 47, antiga Rodovia Rio-São Paulo, C.P. 74505, 23851-970, Seropédica, RJ. E-mail: bruno@cnpab.embrapa.br

${ }^{3}$ Engenheiro Agrônomo, Doutor, Pesquisador científico, Embrapa - Agrobiologia. E-mail: segundo@cnpab.embrapa.br

${ }^{4}$ Engenheiro Agrônomo, Doutor, Professor adjunto, UFU. E-mail: dgsantana@umuarama.ufu.br 
CT was $895 \mathrm{~kg}$ grain ha $\mathrm{ha}^{-1}$ in the sequence oil radish-corn under $N T$, and 1,166 and $166 \mathrm{~kg}_{\text {grain }} \mathrm{ha}^{-1}$ in the sequences milletcorn and oil radish-corn, respectively.

Key words: pre-plant applied $N$, Zea mays, winter crops residues, $\mathrm{N}$ efficiency, ${ }^{15} \mathrm{~N}$ tracer, $\mathrm{NH}_{3}-\mathrm{N}$ volatilization.

\section{INTRODUÇÃO}

A importância da cultura antecessora à cultura principal em sistema plantio direto (SPD) tem sido mostrada em diversos trabalhos, com maiores alternativas no Sul do país (AMADO \& MIELNICZUK, 1999) em relação ao Cerrado (SPEHAR \& LARA CABEZAS, 2001), pelas condições climáticas mais favoráveis. A cultura antecessora já se constitui num dos critérios para a recomendação da adubação nitrogenada para a cultura do milho em SPD, nos Estados de Santa Catarina e Rio Grande do Sul (AMADO et al., 2002). O maior benefício para o milho tem sido registrado, no Sul do país (ROS \& AITA, 1996), pelo uso preferencial de leguminosas que podem reduzir a demanda de $\mathrm{N}$ em 50 a $70 \%$. Na região do Cerrado, especificamente no Triângulo Mineiro-MG, existe limitação climática para o uso de leguminosas antecendo ao milho (ALVARENGA et al., 2001). Associado à cultura antecessora, a prática de risco da adubação nitrogenada em pré-semeadura do milho no Sul, torna-se interessante em condições de pluviosidade regular (WIETHÖLTER, 2000; CERETTA et al., 2002). Nestas condições, o adubo aplicado em pré-semeadura favorece indiretamente a cultura do milho, à medida em que o $\mathrm{N}$ mineralizado da matéria orgânica do solo (MOS) e o $\mathrm{N}$ do fertilizante, temporariamente imobilizado nos resíduos (LARA CABEZAS et al., 2001), fica disponível para o milho, além do $\mathrm{N}$ derivado da decomposição dos resíduos, acelerada pela própria adubação nitrogenada (ZOTARELLI et al., 2002). O fato de haver estiagem prolongada no Cerrado seria um ponto favorável para o sucesso dessa prática. Sendo assim, o presente trabalho teve como objetivos: a) quantificar a produção de MMS e o N reciclado pelas culturas de inverno em SPD e SP e a posterior decomposição do material de cobertura até a semeadura do milho em SPD; b) avaliar perdas por volatilização de amônia de fontes nitrogenadas aplicadas em pré-semeadura e cobertura em ambos os sistemas de preparo; e c) quantificar a eficiência do adubo nitrogenado aplicado em présemeadura ( $70 \%$ da dose) e em cobertura (30\%) na cultura de milho e seu efeito na produtividade do milho, em dois sistemas de sucessão: milheto - milho e nabo forrageiro - milho em SPD e SP, na região do Triângulo Mineiro, MG.

\section{MATERIAL E MÉTODOS}

O experimento foi instalado na fazenda Floresta do Lobo, Rodovia BR - 050, km 93, município de Uberlândia (MG), em LATOSSOLO VERMELHO Ácrico típico, fase cerrado, de vegetação subcaducifólia, contendo $710 \mathrm{~g} \mathrm{~kg}^{-1}$ de argila na camada de $0-10 \mathrm{~cm}$ de profundidade. A caracterização química do solo, em SPD, foi realizada em setembro de 1998 , nas camadas de 0 a 10 e 10 a $20 \mathrm{~cm}$ de profundidade apresentando, respectivamente: pH (água) 6,1 e 5,6; P (Mehlich 1) 16,2 e 3,0 $\mathrm{mg} \mathrm{dm}^{-3}$; K (Mehlich 1) 3,21 e $0,72 \mathrm{mmol}_{\mathrm{c}} \mathrm{dm}^{-3}$; CTC 70,0 e 50, $0 \mathrm{mmol}_{\mathrm{c}} \mathrm{dm}^{-3}$; saturação por bases 73,0 e $52 \%$ e MO 45,0 e 36, $0 \mathrm{~g} \mathrm{dm}^{-3}$. Em SP, após o revolvimento do solo, na camada de 0 a $20 \mathrm{~cm}$ de profundidade, o solo apresentou: $\mathrm{pH}$ (água) 5,8; $\mathrm{P}$ (Mehlich 1) 7,7 $\mathrm{mg} \mathrm{dm}^{-3} ; \mathrm{K}$ (Mehlich 1) 1,87 $\mathrm{mmol}_{\mathrm{c}} \mathrm{dm}^{-3}$; CTC $60,0 \mathrm{mmol}_{\mathrm{c}} \mathrm{dm}^{-3}$; saturação por bases $71,0 \% \mathrm{e}$ MO 41, $0 \mathrm{~g} \mathrm{dm}^{-3}$. Deve-se destacar que o tratamento SP, foi assim denominado, porque em outubro de 1997 , após quatro anos agrícolas sob SPD, o preparo para a semeadura foi feito com aração e gradagem. A área esteve sob SPD em cultivo alternado de milho e soja nas safras de verão, e gramíneas (aveia preta, sorgo forrageiro e milheto), com a finalidade de proporcionar cobertura do solo, no outono e inverno.

Em cada sistema de preparo foi empregado o delineamento de blocos casualizados, em esquema de faixas (para facilitar as operações de campo), com quatro repetições. As parcelas principais (45,0 x 10,4m) foram constituídas por dois sistemas de sucessão de culturas: milheto - milho e nabo forrageiro - milho. O SP constou de uma aração na profundidade de 15 a $20 \mathrm{~cm}$ e uma passagem de grade niveladora. As subparcelas foram constituídas de dois tratamentos: a) adubação completa, como realizado no restante da área comercial, e b) ausência de nitrogênio na adubação de fundação e cobertura, com aplicação dos outros nutrientes, no cultivo do milho.

Embora pouco usual, na área destinada a SP, no outono - inverno de 1998, foram semeadas as mesmas espécies que em SPD, sendo incorporadas após a passagem de rolo-faca.

No SPD, após a colheita da safra da soja 97/98 (10/03/98), foram realizadas oito amostragens ao acaso, em quadrante de $1 \mathrm{~m}^{2}$, com a finalidade de estimar a MMS (seca em estufa a $60^{\circ} \mathrm{C}$ até peso constante) e o conteúdo de $\mathrm{N}$ na cobertura morta (digestão-destilação Kjeldahl). Durante o ciclo das culturas de inverno e até à semeadura de milho (março 
a setembro de 1998), foram avaliadas a matéria seca e o N-residual do material em decomposição. Em quatro das oito parcelas, foram instaladas cinco microparcelas de $0,2 \times 0,2 \mathrm{~m}$, nas quais se colocou o equivalente em material fresco, existente na ocasião. As microparcelas foram cobertas com sombrite a uma altura de $0,1 \mathrm{~m}$ para evitar a deposição de material externo no local. A correção de MMS, devido a possível presença de solo nas amostras dos resíduos, foi feita através da análise de cinzas, após ignição das mesmas, segundo REZENDE et al., (1999). Em ambos os sistemas de preparo, o nabo forrageiro foi semeado em 17/03/98 e o milheto em 22/03/98. As culturas foram semeadas em linhas, espaçadas de $0,15 \mathrm{~m}$, com densidade de semeadura de 15 e $25 \mathrm{~kg} \mathrm{ha}^{-1}$ de sementes para o nabo forrageiro e milheto, respectivamente, sem adubação nem tratamento fitossanitário das sementes. $\mathrm{Na}$ ocasião de pleno florescimento (3/06/98), em SPD, foi avaliada a produção de MMS e o $\mathrm{N}$ acumulado na parte aérea, em oito repetições, sendo as plantas cortadas a $5 \mathrm{~cm}$ da superfície do solo. Os valores obtidos foram somados à cobertura morta existente nesta ocasião.

Em 14/11/98, foi semeado o híbrido de milho Exceler (triplo), semi - precoce, numa densidade de 62.500 plantas ha $^{-1}$, espaçamento de $0,8 \mathrm{~m}$, sobre uma resteva estimada em $3.124 \mathrm{~kg} \mathrm{ha}^{-1}$, em média, no tratamento antecedido pelo nabo forrageiro, e em $3.901 \mathrm{~kg} \mathrm{ha}^{-1}$, no tratamento antecedido pelo milheto, na área sob SPD. No sulco de semeadura, para todos os tratamentos com adubação nitrogenada, realizouse a aplicação de 36, 90 e $54 \mathrm{~kg} \mathrm{ha}^{-1}$ de $\mathrm{N}, \mathrm{P}_{2} \mathrm{O}_{5}$ e $\mathrm{K}_{2} \mathrm{O}$ formado por sulfato de amônio ( $\mathrm{SA}$ ), fosfato monoamônico e superfosfatosimples amoniado e $\mathrm{KCl}$ ). Foram adicionados também 1,$2 ; 0,45 ; 0,18 ; 0,9 ; 1,8 \mathrm{e}$ $0,36 \mathrm{~kg} \mathrm{ha}^{-1}$ de $\mathrm{Zn}, \mathrm{B}, \mathrm{Cu}, \mathrm{Fe}, \mathrm{Mn}$ e Mo, respectivamente. Em pré-semeadura (7/11/98), foram aplicados em sulcos, com espaçamento de $0,4 \mathrm{~m}$, a 5$7 \mathrm{~cm}$ de profundidade, $70 \mathrm{~kg} \mathrm{ha}^{-1}$ de $\mathrm{N}$ e $70 \mathrm{~kg} \mathrm{ha}^{-1} \mathrm{de}$ $\mathrm{K}_{2} \mathrm{O}$ misturando-se uréia (U) e SA na razão de 4:1 e KCl. No estádio de 4 a 5 folhas, foi aplicado a lanço, nas entrelinhas, $35 \mathrm{~kg} \mathrm{ha}^{-1}$ de $\mathrm{N}$ na forma de $\mathrm{SA}$, utilizando-se um sistema pendular de distribuição. Nos tratamentos em que foi omitida a aplicação de $\mathrm{N}$, foram aplicados todos os outros nutrientes nas doses e épocas correspondentes. Em cada sistema de preparo de solo, nos tratamentos que receberam $\mathrm{N}$ em présemeadura e cobertura, foi instalada uma microparcela por parcela, de forma aleatória, com dimensões de $1,5 \mathrm{~m}$ de comprimento por 1,6m de largura, constituída pelo sulco de adubação eqüidistante às duas linhas adjacentes, que seriam posteriormente semeadas (présemeadura), ou já semeadas, no caso do tratamento de adubação em cobertura. Nessas microparcelas, foram substituídos os adubos nitrogenados comerciais, pela aplicação de uma mistura de uréia marcada $(46,7 \% \mathrm{~N}), \operatorname{com} 2,241 \%$ de átomos de ${ }^{15} \mathrm{~N}$ em excesso, e sulfato de amônio $(21,4 \% \mathrm{~N})$, com $2,183 \%$ de átomos de ${ }^{15} \mathrm{~N}$ em excesso, em dose equivalente a $71,3 \mathrm{~kg} \mathrm{ha}^{-1}$ de N. Nos tratamentos que receberam $\mathrm{N}$ no estádio de 4 a 5 folhas, foi instalada uma microparcela, de $3,0 \mathrm{~m}$ de comprimento e $0,8 \mathrm{~m}$ de largura por parcela, com aplicação de $35,7 \mathrm{~kg} \mathrm{ha}^{-1}$ de $\mathrm{N}$, a lanço na entrelinha, fornecido na forma de sulfato de amônio, com $2,183 \%$ de átomos de ${ }^{15} \mathrm{~N}$ em excesso.

$\mathrm{O} \mathrm{N}-\mathrm{NH}_{3}$ volatilizado, proveniente da aplicação parcelada de $\mathrm{N}$ (pré-semeadura e cobertura), foi determinado somente na sucessão nabo-milho, em ambos os sistemas de preparo do solo, devido à limitada disponibilidade de aparelhos coletores de amônia. Foi utilizada a metodologia e o coletor de amônia semiaberto estático calibrado por LARA CABEZAS et al. (1999), com dez repetições para cada tratamento. $\mathrm{Na}$ época da colheita (29/03/99), foi determinada a produtividade de grãos (umidade corrigida para $130 \mathrm{~g}$ $\mathrm{kg}^{-1}$ ) em SPD e SP. Nas microparcelas que receberam adubo marcado com ${ }^{15} \mathrm{~N}$ em pré-semeadura, foram colhidas as plantas no interior do metro linear central das duas linhas da microparcela. O material foi fracionado em parte aérea (palha + colmo + sabugo) e grãos. O N da parte aérea e grãos foi determinado por via seca Dumas (RAMOS et al., 2001), e posterior determinação da abundância de ${ }^{15} \mathrm{~N}$ por espectrometria de massas, na Embrapa Agrobiologia, Seropédica, RJ. Efetuaram-se os cálculo da percentagem e da quantidade de nitrogênio $\left(\mathrm{kg} \mathrm{ha}^{-1}\right)$ no grão e parte aérea derivada do fertilizante (Nppf) e a recuperação do Nfertilizante (\%) de acordo com LARA CABEZAS et al., (2000). O Nppf de cada adubação nitrogenada (présemeadura e cobertura) foi somado e calculada a eficiência total do $\mathrm{N}$-fertilizante, em relação ao $\mathrm{N}$ total aplicado (107,0kg ha $\left.{ }^{-1}\right)$. A comparação das médias das variáveis avaliadas, entre os sistemas de preparo de solo e sucessão de culturas, foi realizada pelo teste $\mathrm{t}$ de Student, a 5\% de significância

\section{RESULTADOSE DISCUSSÃO}

Após a colheita da soja, realizada em 7/03/ 98, a resteva foi incorporada em SP (não quantificada) e a cobertura morta estimada na área de SPD em $6.725 \mathrm{~kg} \mathrm{ha}^{-1}$ de MMS com 106,9kg ha-1 de N. Até o pleno florescimento das culturas de inverno (3/06/98), quando foram acamadas com rolo-faca, em SPD e SP, o nabo forrageiro produziu, em média, 2.274 e $2.546 \mathrm{~kg}$ $\mathrm{ha}^{-1}$ de MMS, e uma acumulação de $\mathrm{N}$ de 53,0 e 61,6kg 
ha $^{-1}$, respectivamente. Estas quantidades, embora aquém do observado na região Sul, estão dentro do esperado para a região do Cerrado (ALVARENGA et al., 2001). Por sua vez, o milheto alcançou os respectivos valores médios em SPD e SP de 5.202 e $5.101 \mathrm{~kg} \mathrm{ha}^{-1}$ de MMS e 107,8 e $104,1 \mathrm{~kg} \mathrm{ha}^{-1}$ de acumulação de $\mathrm{N}$.

A distribuição da pluviosidade, a decomposição da cobertura morta e o N-residual, referentes ao SPD, no período de desenvolvimento vegetativo das culturas de inverno até o acamamento (3/06/08), constam na figura 1 . A pluviosidade acumulada foi de $315,5 \mathrm{~mm}$ em 78 dias, representando, em média, $4 \mathrm{~mm}$ dia $^{-1}$, porém com estiagens freqüentes (Figura 1a). Nesse intervalo de tempo, sob nabo forrageiro (Figura 1b), houve decomposição média de resíduos de soja e resíduos anteriores (milho e aveia preta) estimada em $1.914 \mathrm{~kg} \mathrm{ha}^{-1}$ e uma liberação de $40,4 \mathrm{~kg} \mathrm{ha}^{-1}$ de $\mathrm{N}$, equivalente a 76,2\% do $\mathrm{N}$ acumulado pela cultura $([40,4 / 53,0]$ x 100). Sob milheto, houve decomposição média estimada de $1.150 \mathrm{~kg} \mathrm{ha}^{-1} \mathrm{e} 40,3 \mathrm{~kg}$ ha $^{-1}$ de $\mathrm{N}$ foram disponibilizados ao sistema (Figura 1c), equivalente a $37,4 \%$ do $\mathrm{N}$ acumulado pelo milheto ([40,3/107,8] x 100). Na época do acamamento do nabo forrageiro, em SPD, 79 dias após a semeadura, foram adicionados $2.274 \mathrm{~kg} \mathrm{ha}^{-1}$ de MMS de parte aérea, contendo $53,0 \mathrm{~kg} \mathrm{ha}^{-1}$ de $\mathrm{N}$ (relação $\mathrm{C} / \mathrm{N}=24,9$, assumindo $58 \%$ de $\mathrm{C}$ ), que somados à cobertura morta residual, e ao $\mathrm{N}$-residual, estimados a partir dos modelos (Figura 1b) totalizaram $6.545 \mathrm{~kg} \mathrm{ha}^{-1}$ de MMS e 98,6 kg ha-1 de N, sobre a superfície do solo. De forma similar, após o acamamento do milheto, 74 dias após a semeadura, foram adicionados ao sistema $5.202 \mathrm{~kg} \mathrm{ha}^{-}$ ${ }^{1}$ de MMS e 107,8 $\mathrm{kg} \mathrm{ha}^{-1}$ de $\mathrm{N}$ (relação $\mathrm{C} / \mathrm{N}=28,0$ ), que somados à cobertura morta e ao N-residual, estimados pelos modelos utilizados (Figura 1c), significaram $10.387 \mathrm{~kg} \mathrm{ha}^{-1}$ de MMS e $153,9 \mathrm{~kg} \mathrm{ha}^{-1}$ de $\mathrm{N}$, na superfície do solo. Longos períodos de estiagem foram observados após o acamamento das culturas de inverno em SPD (3/06/98) até a semeadura de milho (13/11/98), conforme pode ser observado na distribuição da pluviosidade durante o período (Figura 2a). Houve decomposição média, estimada nesse período, de $4.019 \mathrm{~kg} \mathrm{ha}^{-1}$ de MMS, e liberação de 77,3kg $\mathrm{ha}^{-1}$ de N, na sucessão nabo-milho (Figura 2b). Por sua vez, na sucessão milheto-milho (Figura 2c), houve decomposição média de MMS estimada em $8.022 \mathrm{~kg}$ ha $^{-1}$, e liberação de $130,7 \mathrm{~kg} \mathrm{ha}^{-1}$ de N. Em ambas as sucessões, o $\mathrm{N}$ liberado pela decomposição da cobertura morta superou o $\mathrm{N}$ contido nos resíduos das culturas de inverno, indicando que a decomposição dos restos culturais assinalados foi importante na liberação de N. Como as quantidades residuais de matéria seca e $\mathrm{N}$ da cobertura morta não mostraram diferenças significativas ao final da época de avaliação, o tratamento com palha de milheto aumentou a disponibilidade de $\mathrm{N}$ ao sistema (Figura 2).

As perdas acumuladas de $\mathrm{N}-\mathrm{NH}_{3}$ volatilizado, provenientes do $\mathrm{N}$ aplicado em présemeadura e em cobertura, respectivamente, foram inferiores a 2,0\% do $\mathrm{N}$ aplicado $\left(71,3 \mathrm{~kg} \mathrm{ha}^{-1} \mathrm{de} \mathrm{N}\right)$, tanto em SPD como SP, quando as fontes foram incorporadas em pré-semeadura. A aplicação superficial de sulfato de amônio, feita a lanço, na ocasião da cobertura, causaram perdas estimadas e inferiores a $14,0 \%$ do $\mathrm{N}$ aplicado (em torno de $5 \mathrm{~kg} \mathrm{ha}^{-1} \mathrm{de} \mathrm{N}$ ), em ambos os sistemas de manejo. Estes resultados corroboram com os obtidos por LARA CABEZAS et al. (2000).

A tabela 1 mostra que em SPD houve maior produção de matéria seca $\left(21.139 \mathrm{~kg} \mathrm{ha}^{-1}\right), \mathrm{N}$-total acumulado na planta $\left(239,5 \mathrm{~kg} \mathrm{ha}^{-1}\right)$, recuperação do $\mathrm{N}$-fertilizante $\left(36,2 \mathrm{~kg} \mathrm{ha}^{-1}\right)$ e eficiência de recuperação (50,8\% do N aplicado) no milho cultivado em sucessão com milheto do que em sucessão a nabo forrageiro. Estes resultados têm a influência do milheto, que apresentou maior quantidade de $\mathrm{N}$ acumulado na parte aérea e maior disponibilidade de $\mathrm{N}$ na fase de decomposição, após o acamamento (Figura 2). Por sua vez, em SP, não foi observada diferença significativa em ambas as sucessões (Tabela 1). Nesta condição, não houve efeito da cultura antecessora em função da incorporação prévia de restevas, que já mineralizadas, não teriam afetado o comportamento da biomassa microbiana quanto à imobilização.

A tabela 2 mostra que, para a adubação em cobertura, não houve diferença significativa quanto à recuperação de $\mathrm{N}$-fertilizante na planta e eficiência entre as sucessões, nos tratamentos de preparo do solo. Na aplicação de $\mathrm{N}$ em cobertura, em SPD, as eficiências de recuperação de $\mathrm{N}$ fertilizante foram de 72,0 e $69,7 \%$ do aplicado nas sucessões de nabomilho e milheto-milho, respectivamente. Em SP foram, respectivamente, de 80,4 e 75,7\%. ZOTARELLI et al. (2002), trabalhando com as mesmas doses de $\mathrm{N}$ na forma de SA, mostraram, também, maior eficiência de recuperação de $\mathrm{N}$ fertilizante aplicado em cobertura, em relação a pré-semeadura. O N-fertilizante acumulado na planta (pré-semeadura + cobertura) nas sucessões e sistemas de preparo de solo foram de $57,1 \%\left(61,1 \mathrm{~kg} \mathrm{ha}^{-1}\right.$ do N-aplicado) e $42,1 \%\left(45 \mathrm{~kg} \mathrm{ha}^{-1}\right)$ nas sucessões milheto-milho e nabo-milho, respectivamente, em SPD. Em SP foram, respectivamente, $46,8 \%$ e $46,3 \%$ do $\mathrm{N}$-aplicado.

Em SPD, na ausência de adubação nitrogenada, em sucessão à nabo (Figura 3), a 


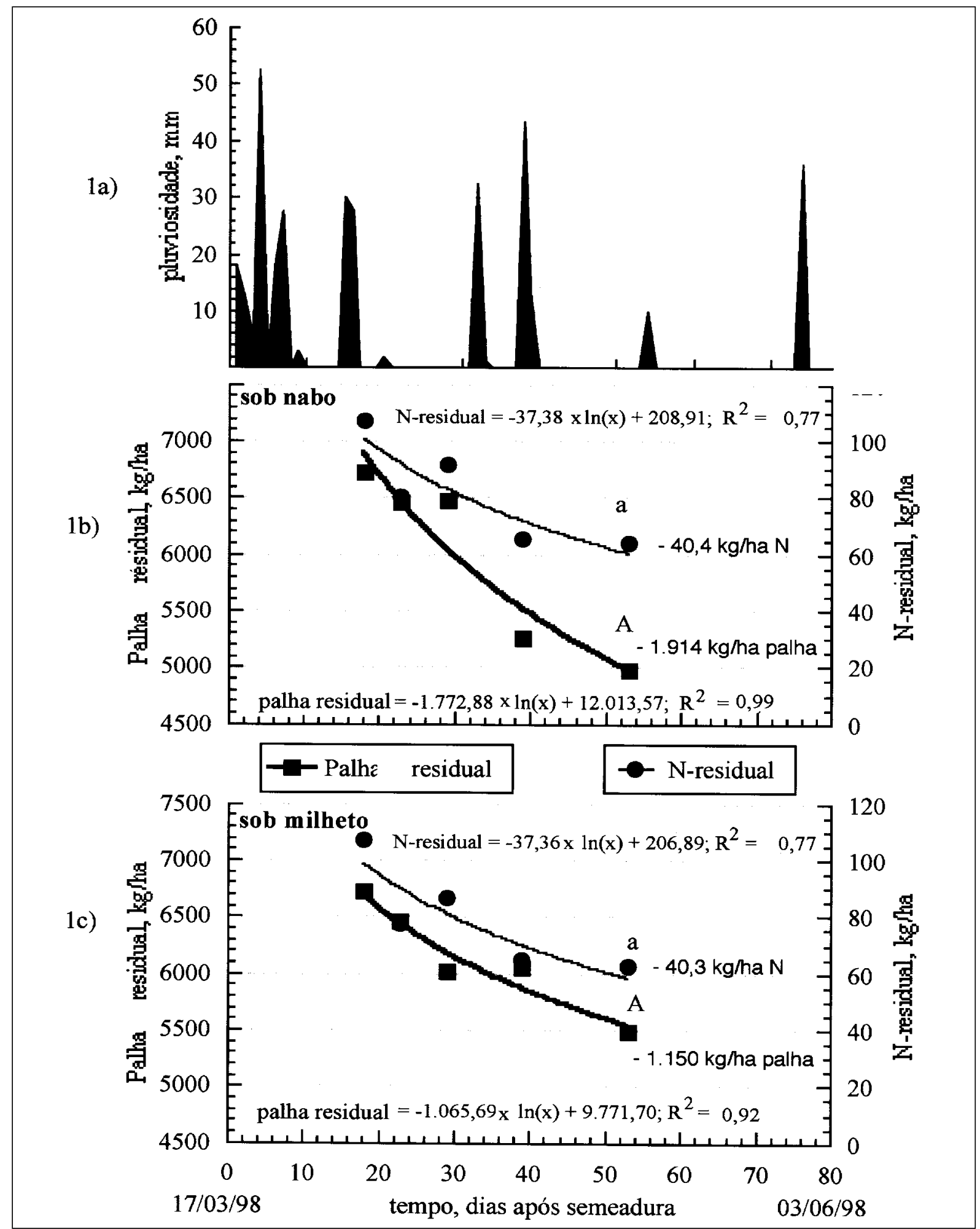

Figura 1 - Distribuição da pluviosidade (a) e decomposição da palha remanescente (milho +aveia preta + soja ) e N-residual da palha sob nabo forrageiro (b) e sob milheto (c).Entre as sucessões, para a MMS residual, as médias seguidas de letras maiúsculas iguais, não diferem entre si pelo teste " $\mathrm{t}$ " de Students ao nível de 5\% de significância.Entre sucessões , para o N-residual, as médias seguidas de letras minúsculas iguais não diferem entre si pelo teste "t" de Students em nível de 5\% de significância.

Ciência Rural, v. 34, n.4, jul-ago, 2004. 


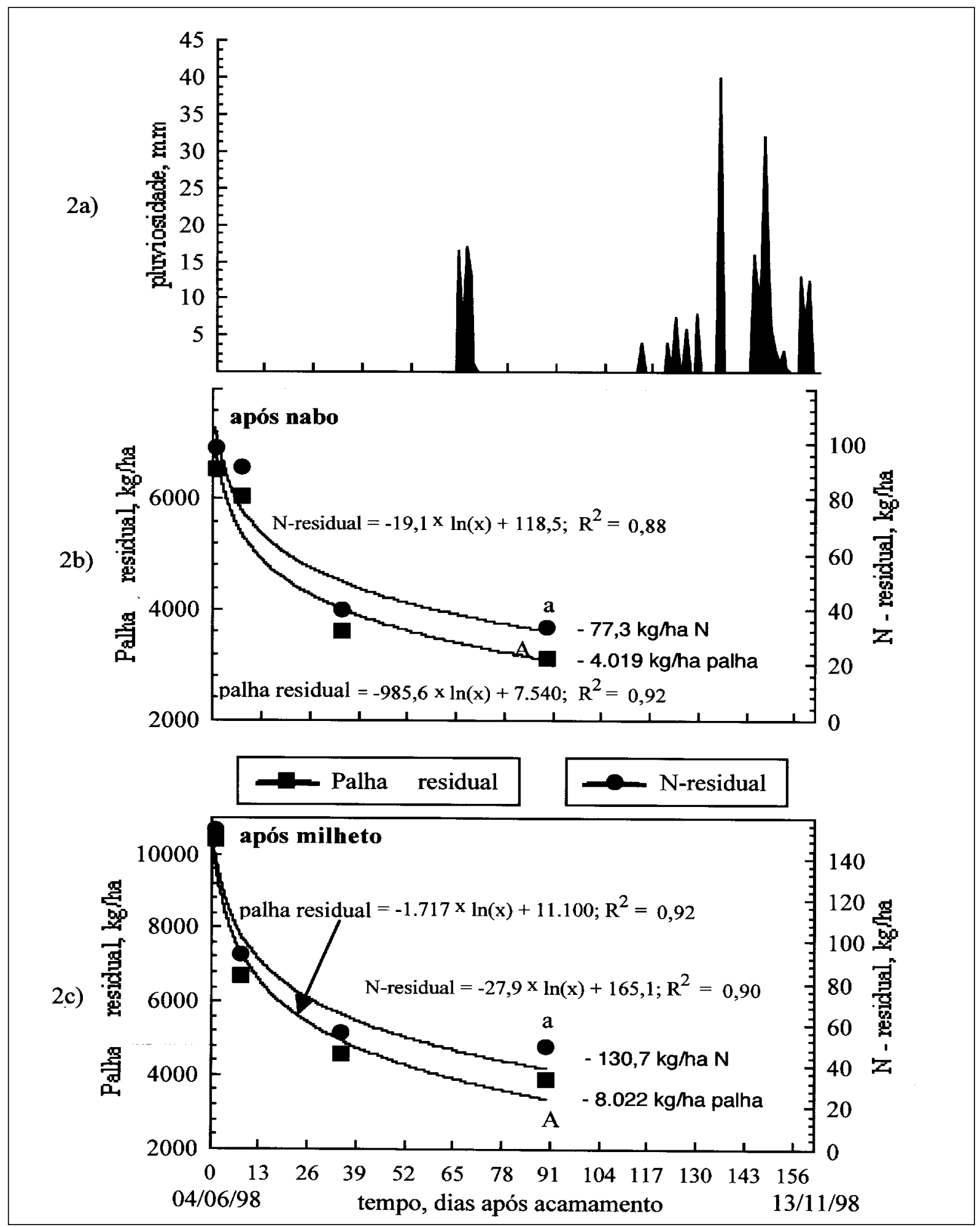

Figura 2 - Distribuição da pluviosidade (a) e decomposição da palha remanescente (milho + aveia preta + soja) e N-residual da palha, após o acamamento do nabo forrageiro (b) e após milheto (c).Entre as sucessões, para a MMS residual, as médias seguidas de letras maiúsculas iguais, não diferem entre si pelo teste "t" de Students ao nível de 5\% de significância.Entre sucessões , para o N-residual, as médias seguidas de letras minúsculas iguais não diferem entre si pelo teste "t" de Students em nível de 5\% de significância. 

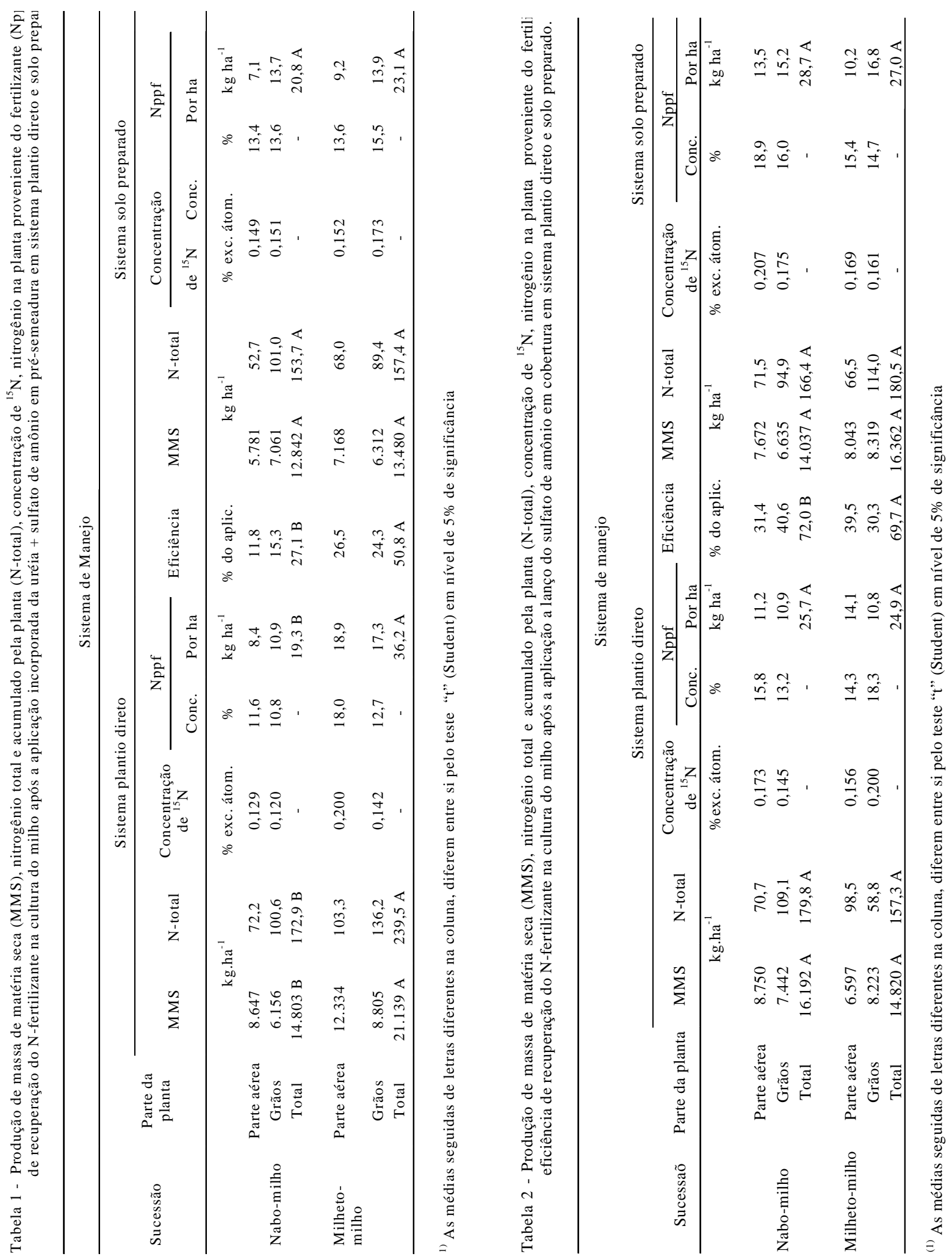

Ciência Rural, v. 34, n.4, jul-ago, 2004. 


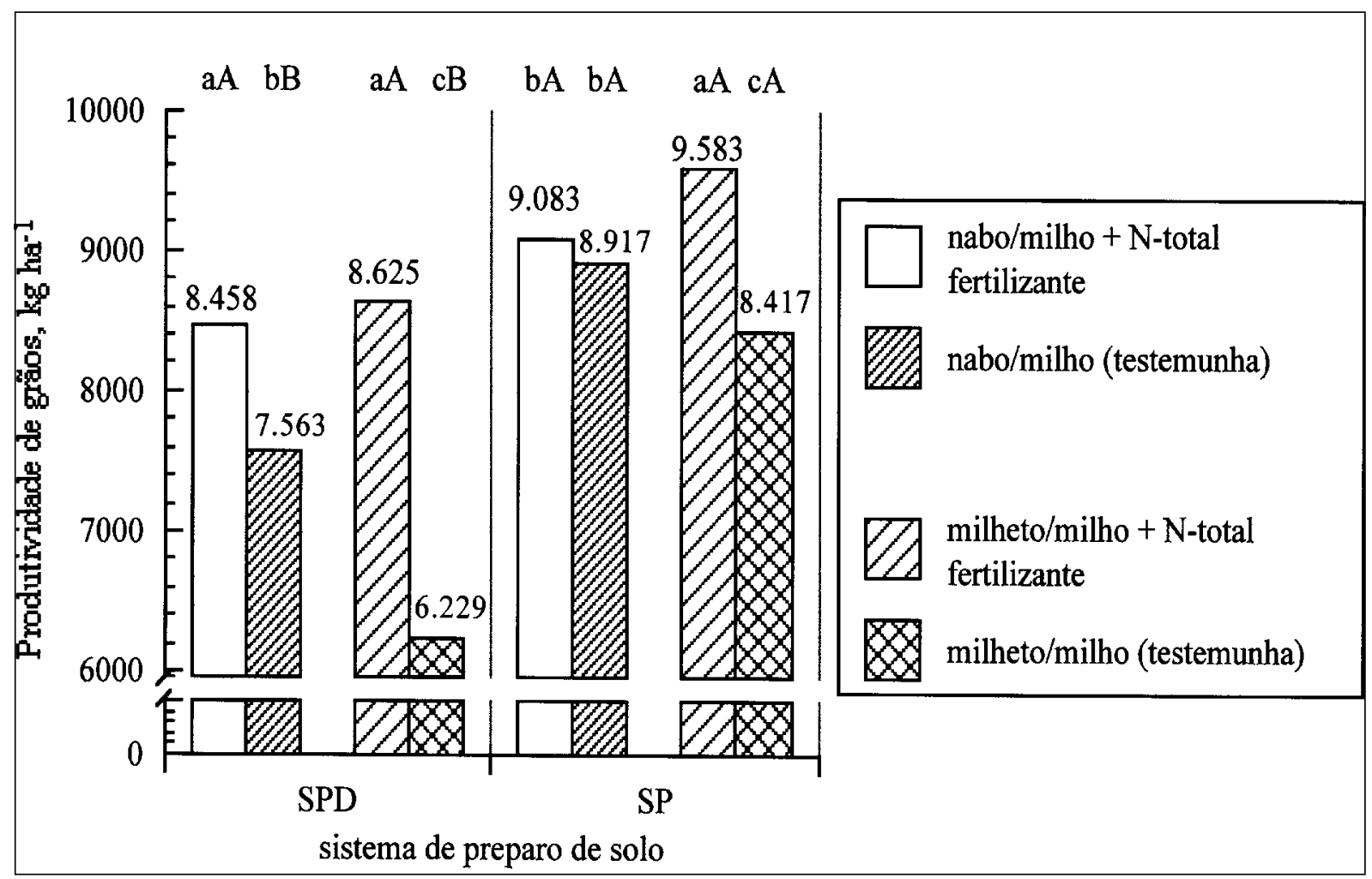

Figura 3 - Produtividade de grãos de milho em sucessão as culturas de milheto e nabo forrageiro em SPD e SP.Dentro de cada sistema de preparo de solo, entre sucessões com e sem adubação nitrogenada de cobertura, as médias seguidas de letras minúsculas desiguais diferem entre si pelo teste de " $\mathrm{t}$ " de students em nível de 5\% de significância.Entre sistema de preparo de solo, na mesma sucessão, com e sem adubação nitrogenada de cobertura, as médias seguidas de letras maiúsculas iguais, não diferem entre si pelo teste de "t" de students em nível de 5\% de significância.

produtividade de milho $\left(7.563 \mathrm{~kg} \mathrm{ha}^{-1}\right)$ foi superior à sucessão com milheto $\left(6.229 \mathrm{~kg} \mathrm{ha}^{-1}\right)$, indicando que maior quantidade de $\mathrm{N}$ foi disponibilizado na sucessão nabo-milho. Por sua vez, em SP, as produtividades foram, respectivamente, de $8.917 \mathrm{e}$ $8.417 \mathrm{~kg} \mathrm{ha}^{-1}$, mostrando que a incorporação das restevas (adubação verde) deve ter disponibilizado maior quantidade de $\mathrm{N}$ em relação à $\mathrm{SPD}$, e que o nabo foi mais favorável para o milho que o milheto. Na presença de N, verificou-se na sucessão milhetomilho, acréscimo médio de $2.396 \mathrm{~kg} \mathrm{ha}^{-1}$ de grãos em relação à testemunha (Figura 3). Em SP, verificou-se que o efeito da adubação com $\mathrm{N}$ mostrou acréscimos muito inferiores em produtividade em relação à testemunha: 166 e $1.166 \mathrm{~kg} \mathrm{ha}^{-1}$ de grãos nas sucessões nabo-milho e milheto-milho, respectivamente. Nesta condição, em que se fez a incorporação da cobertura morta no solo, a maior disponibilidade de $\mathrm{N}$ do solo, pela maior mineralização de $\mathrm{N}$ em relação ao SPD, poderia ter contribuído para uma menor eficiência da recuperação do $\mathrm{N}$ fertilizante.

\section{CONCLUSÕES}

Tanto em SPD como em SP, a produção de matéria seca e acumulação de $\mathrm{N}$ pelo milheto foram superiores às observadas com nabo forrageiro. A decomposição de resíduos e a correspondente liberação de N, foi afetada tanto na presença quanto na ausência de adubação nitrogenada, aplicada em pré-semeadura. As perdas de $\mathrm{N}$ observadas através da volatilização de $\mathrm{NH}_{3}$ foram desprezíveis. Em pré-semeadura a eficiência do fertilizante foi superior na sucessão milheto-milho do que na sucessão nabo-milho em SPD, sendo similares em SP, quando as culturas de inverno foram incorporadas ao solo. Maiores rendimentos de milho foram observados com a incorporação dos resíduos (SP), com uma influência menor da adubação nitrogenada, comparando-se com o observado em SPD.

\section{AGRADECIMENTOS}

Os autores agradecem à Fundação de Amparo à Pesquisa do Estado de Minas Gerais (FAPEMIG), pelo apoio financeiro outorgado para o estudo bem como aos discentes 
do ICIAG/UFU, pela execução dos trabalhos de campo e laboratório.

\section{REFERÊNCIAS BIBLIOGRÁFICAS}

ALVARENGA, R.C. et al. Plantas de cobertura de solo para sistema plantio direto. Informe Agropecuário, Belo Horizonte, v.22, n.208, p.25-36, 2001.

AMADO, T.J.C; MIELNICZUK, J. Plantio direto e rotação de culturas com leguminosas. Revista Plantio Direto, Passo Fundo, n.50, p.23-27, 1999.

AMADO, T.J.C. et al. Recomendação de adubação nitrogenada para o milho no RS e SC adaptada ao uso de culturas de cobertura do solo, sob sistema plantio direto. Revista Brasileira de Ciência do Solo, Viçosa, v.26, n.1, p.241-248, 2002.

CERETTA, C.A. et al. Nitrogen fertilizer split-application for corn in no-till sucession to black oats. Scientia Agricola, Piracicaba, v.59, n.3, p.549-554, 2002.

LARA CABEZAS, W.A.R. et al. Calibration of a semi-open static collector for determination of ammonia volatilization from nitrogen fertilizers. Communications in Soil Science and Plant Analysis, New York, v.30, p.389-406, 1999.

LARA CABEZAS, W.A.R. et al. Balanço da adubação nitrogenada sólida e fluida de cobertura na cultura de milho, em sistema plantio direto no Triângulo Mineiro (MG). Revista
Brasileira de Ciência do Solo, Viçosa, v.24, p.363-376, 2000 .

REZENDE, C.P. et al. Litter deposition and disappearance in Brachiaria pastures in the Atlantic forest region of the South of Bahia, Brazil. Nutrient Cycling in Agroecosystems, Netherlands, v.54, n.2, p.99-112, 1999.

ROS, C.O.; AITA, C. Efeito de espécies de inverno na cobertura do solo e fornecimento de nitrogênio ao milho em plantio direto. Revista Brasileira de Ciência do Solo, Campinas, v.20, p.135-140, 1996.

SPEHAR, C.; LARA CABEZAS, W.A.R. Introdução e diversificação de espécies para a diversificação do sistema produtivo nos cerrados. In: LARA CABEZAS, W.A.R; FREITAS, P.L. Plantio direto na integração lavourapecuária. 2.ed. Uberlândia : Universidade Federal de Uberlândia, 2001. p.179-188.

WIETHÖLTER, S. Manejo da fertilidade do solo na cultura do milho. In: SEMINÁRIO SOBRE TECNOLOGIA DE PRODUÇÃO E COMERCIALIZAÇÃO DO MILHO, 2000, Passo Fundo. Resumo de palestras... Passo Fundo : Aldeia Norte, 2000. p.5-38.

ZOTARELLI, L. et al. Recuperação do $\mathrm{N}$ derivado do fertilizante pela cultura do milho em sistema plantio direto. In: REUNIÃO BRASILEIRA DE FERTILIDADE DO SOLO E NUTRIÇÃO DE PLANTAS, 25., 2002, Rio de Janeiro. Anais... Rio de Janeiro : UFRRJ, 2002. p. 91 . 